RAD Conference Proceedings, vol. 2, pp. 231-236, 2017

www.rad-proceedings.org

novororitty

\title{
SKIN PROTECTION AGAINST SOLAR UV RADIATION BY NATURAL PLANT PRODUCTS: EXTRACTS FROM ELDER FRUIT (SAMBUCUS NIGRA L.)
}

\author{
Milica Stankovićc ${ }^{*}$, Jelena Živković1, Vanja Tadić $^{2}$, Ivana Arsić1 \\ ${ }^{1}$ Department of Pharmacy, Faculty of Medicine, University of Niš, Niš, Serbia \\ ${ }^{2}$ Department for Pharmaceutical Research and Development, Institute for Medicinal Plant Research \\ "Dr Josif Pančić, Belgrade, Serbia
}

\begin{abstract}
Solar radiation has harmful effects on exposed skin, producing accelerated aging processes (wrinkles, dryness, telangiectasia, dyspigmentations). Also, there is an increased ROS generation in skin exposed to the UV-A and $U V-B$ radiation. This results in oxidative stress, photodamage of skin macromolecules and photocarcinogenesis processes. In order to prevent this, botanical extracts with antioxidant properties can be used in anti-photoaging preparations, as a substitute for traditional sunscreen products. Plant extracts, rich in natural polyphenols, exert fewer sensitization effects on skin and are very effective against oxidative damaging caused by UV radiation. The aim of this study was to evaluate the antioxidative activity of different elder (Sambucus nigra L.) fruit extracts. Active components of S. nigra, such as polyphenols, have an important biological activity. Fruit extracts were obtained by the maceration method using four different solvents (methanol - ME, propylene glycol $45 \% v / v-P E$, ethanol $70 \% v / v$ - EE and distilled water - WE). To study antioxidant activity we used different in vitro assays: 2,2-diphenyl-1picrylhydrazyl (DPPH) radical scavenging, ferric reducing antioxidant power (FRAP) assay and $\beta$-carotene bleaching assay. The concentrations at which 50\% of the DPPH radicals were scavenged (IC50) were 3.54, 3.94 and $12.07 \mathrm{mg} / \mathrm{ml}$ for the samples $E E, M E$ and $P E$, respectively. The sample WE showed a stronger scavenging activity (IC5O value was $2.62 \mathrm{mg} / \mathrm{ml}$ ). FRAP values were 242.29 and $686.43 \mu \mathrm{mol} \mathrm{Fe} e^{2+} / \mathrm{g}$ of dry extract for PE and ME samples, respectively. Higher values were obtained using the EE and WE samples, 793.54 and $934.81 \mu \mathrm{mol} \mathrm{Fe}{ }^{2+} / \mathrm{g}$ of dry extract, respectively. Sample EE was the most active in the $\beta$-carotene bleaching assay (IC50 was 0.235 \pm 0.004 $\mathrm{mg} / \mathrm{ml}$ ). Extracts WE and PE showed similar, but lower percentage of inhibition of $\beta$-carotene bleaching. FRAP assay showed a significant $(p<0.05)$ negative correlation $(r=-0.975)$ with radical scavenging capacity (IC5O values). The extract WE (distilled water was used as a solvent) exhibited the highest radical scavenging activity and had the highest ferric reducing potential.
\end{abstract}

Key words: Fruit extracts, natural antioxidants, UV radiation, skin, Sambucus nigra, skin, UV radiation

DOI: $10.21175 /$ RadProc.2017.48

\section{INTRODUCTION}

The exposure to solar ultraviolet (UV) radiation has toxic effects on human skin, and causes many changes and damages of the skin. The major effects are photoaging, erythema, skin tanning and thickening, immunosupression. Solar radiation also causes DNA damage and photocarcinogenesis [1]. Premature aging, melanoma and non-melanoma skin cancers are skin disorders caused by the induction of inflammation [2]. UVB photons are more energetic and are responsible for processes like sunburn, sun tanning and photocarcinogenesis, but UVA rays also play an important role in photoaging [1]. The main symptoms of accelerated skin aging are fine and coarse wrinkling, rough skin texture, dryness, telangiectasia and dyspigmentation abnormalities. Studies show that during the UV exposure there is an increased production of reactive oxygen species (ROS) in the skin. This results in oxidative stress and photodamage of skin proteins and other macromolecules [3]. ROS can damage the DNA, lipid membrane and protein structures in the skin [4].

Skin exposure to solar UV radiation is related to oxidative stress. In recent years, there has been an increasing interest in the use of natural antioxidants as photoprotective agents, for the treatment and prevention of UV-mediated diseases [5]. Although the antioxidative defensive system of the body can neutralize ROS, these protective agents are not enough when there is an excessive amount of oxidative stress. Topical antioxidants have the ability to reduce ROS generated from UV radiation and to provide additional benefits [4].

Many botanical active principles with antioxidant properties can be used in skin photoprotection formulations, alone or like supplements to other sunscreens if they are working through different pathways. This suggests that some plants might be used for the prevention and treatment of human skin disorders. This kind of photoprotection is very important and may be an effective approach for reducing the incidence of photoaging and skin cancer

\footnotetext{
*ms.milicastankovic@yahoo.com
} 
[3]. Also, this approach appears to have practical implications in reducing skin disorders. Unlike the toxic environmental factors that are difficult to control, individuals can modify their dietary habits and lifestyle in combination with the use of skin care products with natural polyphenols to prevent the photodamaging effects in the skin [2]. The use of natural products is favourable in skin photoprotection strategy because of their higher tolerability and insignificant environmental impact. Topical formulations of natural polyphenols or polyphenol-enriched extracts are very effective against oxidative stress and DNA damaging effect of UV radiations on the skin. Plant extracts with good antioxidant activity are good components in photoprotective formulations, as they can prevent ROS generation induced by solar radiation [6].

Polyphenols can absorb a broad spectrum of UV radiation, including UVB and UVA radiation, so they can be very useful in cosmetic sunscreen formulations [7].

Antioxidants from herbal sources represent new possibilities for the prevention and treatment of UVmediated damages. In the last decades, the use of natural plant materials in cosmetics has gained a strong interest, as a safe product for skin application [8]. Also, previous studies suggested that plant polyphenols applied topically had a great potential for the prevention of UV-induced skin damage [9].

Sambucus nigra L. (Adoxaceae), also called elder, is a shrub that grows wild throughout Europe. Sambucus nigra fruits (Figure 1) are used in folk medicine, for the treatment of constipation, as a diuretic and diaphoretic in upper respiratory tract infections and to alleviate pain, reduce inflammation and fever. Also, jams, jellies and wines are made from elder fruits $[10,11]$. In some studies, antiviral activity of the elderberry extract, especially flavonoids from extracts, was demonstrated $[12,13]$.

Elderberry has many components with important biological activity, such as polyphenols (flavonols, phenolic acids, anthocyanins, proanthocyanidins). Because elderberry is a rich source of polyphenols, it is used as an antioxidative agent against the oxidative stress. Fruits from this medicinal plant have beneficial effects on human health [14]. Fruits are also rich in organic acids and sugars which contribute to the health benefits of this plant [15]. Elderberry contains high amount of vitamin $\mathrm{C}, \mathrm{A}$ and $\mathrm{B}$, carotenoids and some minerals [16]. The inflorescence extracts from Sambucus nigra incorporated in sunscreen emulsions were investigated and showed protective properties against UV radiation [7].

The aim of this study was to evaluate the in vitro antioxidant activity of different elder (Sambucus nigra L.) fruit extracts. Extracts were analysed using in vitro test systems: 2,2-diphenyl-1-picrylhydrazyl (DPPH) radical scavenging, ferric reducing antioxidant power (FRAP) assay and $\beta$-carotene bleaching assay.

\section{MATERIALS AND METHODS}

\subsection{Plant materials and reagents}

Fruits of Sambucus nigra were collected from the mountainous Vlasina region of southeastern Serbia. All fruits were collected at the ripened stage (in September). The fruits were harvested randomly according to shape and colour uniformity. Fresh fruits were frozen and stored at $-20^{\circ}$ until further analysis.

2, 2-Diphenyl-1-picrylhydrazyl (DPPH), 2, 4, 6 tripyridyl-s-triazine (TPTZ) and L-ascorbic acid were purchased from Sigma (Sigma-Aldrich $\mathrm{GmbH}$, Germany). Butylated hydroxytoluene (BHT) was purchased from Supelco Analytical (USA). $\beta$-carotene and linoleic acid were obtained from Sigma (SigmaAldrich,USA). 6-hydroxy-2,5,7,8-tetramethylchroman 2 - carboxylic acid (Trolox) was a product of Acros Organics (Denmark). Tween 20 was obtained from Comcen (Serbia). All other chemicals and solvents used were of the high analytical grade.

\subsection{Preparation of the extracts}

Extracts were prepared with four different solvents. Fifty grams of the crushed elder fruits were macerated with $250 \mathrm{ml}$ of solvent (methanol - ME, propylenglycol $45 \% \mathrm{v} / \mathrm{v}-\mathrm{PE}$, ethanol $70 \% \mathrm{v} / \mathrm{v}-\mathrm{EE}$ and distilled water - WE) at room temperature, with mixing twice a day, during five days, protected from light. The obtained extracts were filtered and evaporated to dryness with a rotary evaporator under reduced pressure.

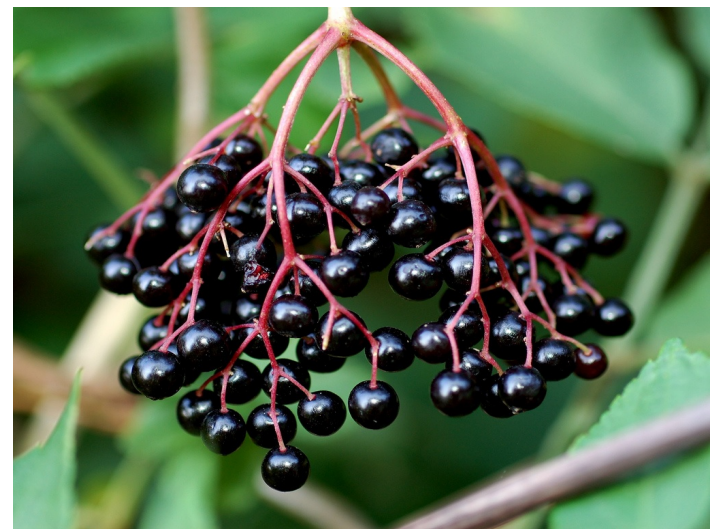

Figure 1. Sambucus nigra L. fruits appearance

\subsection{DPPH (2,2-diphenyl-1-picrylhydrazyl) radical scavenging activity assay}

The DPPH scavenging assay was determined using the method previously described by Espin et al. [17], with some modifications. Briefly, a $80 \mu \mathrm{l}$ aliquot of elderberry extract (sample) in different concentrations was mixed with $2.92 \mathrm{ml}$ of methanol and $1.0 \mathrm{ml}$ of freshly prepared DPPH solution (90 $\mu \mathrm{mol} / \mathrm{l})$. The reaction mixture was shaken vigorously and the decrease in absorbance was measured at $517 \mathrm{~nm}$ after 30 min of incubation in the dark at room temperature. The same procedure was used for the positive controls, trolox and butylated hydroxytoluene (BHT). We used methanol as a reference solution. The scavenging activity was calculated as a percentage (\%) using the following equation (Equation 1):

$$
\text { Percentage of inhibition }(\% \text { RSC })=\frac{\text { Acontrol }- \text { Asample }}{\text { Acontrol }} \times 100
$$

where Acontrol is the absorbance of the control sample (contained methanol instead of sample solution), and 
Asample is the absorbance of the tested extract. Spectrophotometric measurements were performed by using Evolution $60 \mathrm{UV} / \mathrm{Vis}$ scanning spectrophotometer (Thermo Scientific, USA). The obtained values are the means of three independent measurements. The IC5O value (concentration of the extract sample that inhibits 50\% of the free radical concentration) was calculated from the regression equation.

\subsection{Ferric reducing antioxidant potential (FRAP) assay}

The experiment was done according to the method reported by Benzie and Strain [18], with slight modifications. The working FRAP solution was freshly prepared by mixing $300 \mathrm{mM}$ acetate buffer $\mathrm{pH} 3.6$ (6.4 $\mathrm{ml} 2 \mathrm{M}$ sodium acetate solution and $93.6 \mathrm{ml} 2 \mathrm{M}$ acetic acid solution diluted in a $1000 \mathrm{ml}$ volumetric flask), 10 $\mathrm{mM}$ TPTZ in $40 \mathrm{mM} \mathrm{HCl}$ and $20 \mathrm{mM} \mathrm{FeCl}_{3} \times 6 \mathrm{H}_{2} \mathrm{O}$ in 10:1:1 v/v/v. The reaction mixture was obtained by mixing $100 \mu \mathrm{l}$ of extract (final concentration 1.0 $\mathrm{mg} / \mathrm{ml}$ ) or $\mathrm{FeSO}_{4} \times 7 \mathrm{H}_{2} \mathrm{O}$ solution (final concentrations 0.1-1.0 mM) with $3.0 \mathrm{ml}$ of FRAP reagent solution. The mixture was vortexed and the absorbance was measured after $10 \mathrm{~min}$ at $593 \mathrm{~nm}$ using the Evolution $60 \mathrm{UV} /$ Vis scanning spectrophotometer (Thermo Scientific, USA). As a blank we used methanol with FRAP solution instead of a sample. All experiments were carried out in triplicate. The FRAP value was expressed as mmol $\mathrm{Fe}^{2+}$ equivalents/g of dry extract). BHT and L-ascorbic acid were used as positive controls.

\section{5. $\beta$-carotene bleaching assay}

The antioxidant activity (AOA) of the different extract was evaluated using the $\beta$ carotene-linoleic acid assay following the method described by Koleva et al. [19], with some modification. Briefly, $1 \mathrm{~mL}$ of $\beta$ carotene solution in chloroform $(0.2 \mathrm{mg} / \mathrm{mL})$ was transferred into a round-bottomed flask, then $25 \mu \mathrm{L}$ of linoleic acid and $200 \mathrm{mg}$ of Tween 20 were added. The chloroform was evaporated using nitrogen and $50 \mathrm{~mL}$ of oxygenated ultrapure water (obtained by bubbling air through the water for $30 \mathrm{~min}$ ) was added. The mixture was vigorously shaken. The emulsion was freshly prepared before each experiment. Stock solutions of extracts $(1 \mathrm{mg} / \mathrm{mL})$ and reference compound - butylated hydroxytoluene (BHT) (0.1 $\mathrm{mg} / \mathrm{ml}$ ) were prepared.

An aliquot of $200 \mu \mathrm{L}$ of the $\beta$-carotene-linoleic acid emulsion was added to $25 \mu \mathrm{L}$ of different sample concentrations in each well of 96-well microtiter plates. Samples were prepared in triplicate for each concentration used. An equal amount of methanol was used as a control. The plates were shaken on a microplate shaker Vibromix 30 (Tehtnica, Slovenia) at $300 \mathrm{rpm}$ for 5 minutes. The absorbance was measured at $450 \mathrm{~nm}$ using Multiskan Ascent 354 Microplate Reader (Thermo Labsystems, Finland), immediately $\left(\mathrm{t}=\mathrm{O}\right.$ min) and after $120 \mathrm{~min}$ of incubation at $55^{\circ} \mathrm{C}$ in the laboratory incubator (Raypa, Spain). The absorbance measurements were done at $30 \mathrm{~min}$ intervals.

The antioxidant activity (AOA) was calculated as a percentage of inhibition relative to the control using the following equations (Equation 2 and 3):

$$
\begin{aligned}
& \text { AOA }(\%)=\frac{\text { Rcontrol }- \text { Rsample }}{\text { Rcontrol }} \times 100 \\
& R=\frac{\ln \left[A b s\left(t_{0}\right) / A b s\left(t_{120}\right)\right]}{120}
\end{aligned}
$$

where $\operatorname{Abs}\left(t_{0}\right)$ is the absorbance measured at $\mathrm{t}=\mathrm{o} \mathrm{min}$ and $\operatorname{Abs}\left(\mathrm{T}_{120}\right)$ is the absorbance measured after 120 min, according to slightly modified formula from the literature [20]. The extract concentration providing $50 \%$ of $\beta$-carotene bleaching inhibition (IC50) was calculated from the graph of antioxidant activity percentage against extract concentrations $(\mathrm{mg} / \mathrm{ml})$.

\subsection{Statistical analysis}

All analyses were carried out in triplicates. The results of all measurements are expressed as mean \pm standard deviation (SD). Statistical analysis was performed using the Microsoft Excel 2007 and SPSS Statistics 22.0 program package. The data were analyzed using the analysis of variance (ANOVA), HSD Tukey's tests, regression and correlation analysis.

\section{RESULTS AND DISCUSSION}

Many parameters like variety of plant species, growing conditions, maturity stage, time of harvest, transport, handling conditions, as well as storage conditions and sample preparation may affect the chemical composition of investigated fruit. So, it is quite difficult to compare the results between the researchers [21].

We used in vitro techniques for the screening of the antioxidant activity of extracts from Sambucus nigra fruit. Radical scavenging activity has a very important role in prevention of negative effects of toxic free radicals which are formed by UV radiation. In this assay, the antioxidants reduce the stable DPPH radical to the diphenyl-picrylhydrazine by hydrogen donation, and the color changes from violet to yellow. In recent years, this method is widely used for the evaluation of antioxidant activity [22-23].

Radical scavenging activity, expressed as $\mathrm{IC}_{50}$ value (concentration of extracts which inhibits $50 \%$ of free radicals), was the highest for sample PE and that indicates that PE extract has a lower antioxidant capacity than other samples. However, sample WE (water extract) showed the greatest scavenging activity against free radicals. Samples ME and EE showed similar but lower IC50 values. All results are summarized in Table 1. Positive controls trolox and BHT showed IC50 values $1.75 \pm 0.01 \mu \mathrm{g} / \mathrm{ml}$ and $8.20 \pm 0.04 \mu \mathrm{g} / \mathrm{ml}$, respectively.

Table 1. DPPH scavenging activity of the fruit extracts of Sambucus nigra. Values are expressed as mean $\pm \mathrm{SD}(\mathrm{n}=3)$.

\begin{tabular}{|l|c|}
\hline Sample (solvent) & $\begin{array}{c}\mathrm{DPPH}\left(\mathrm{IC}_{50}\right) \\
(\mathrm{mg} / \mathrm{mL})\end{array}$ \\
\hline ME (methanol) & $3.94 \pm 0.01^{*}$ \\
PE (propylene glycol 45\%v/v) & $12.07 \pm 0.03^{*}$ \\
EE (ethanol 70\%v/v) & $3.54 \pm 0.02^{*}$ \\
WE (distilled water) & $2.62 \pm 0.01^{*}$ \\
\hline
\end{tabular}

*values are significantly different at $\mathrm{p}<0.01$ 
A similar study was done by Gamze Duymus et al., where the DPPH radical scavenging activity was the higher in water extracts compare to those with ethanol $70 \%$ and methanol [10]. It is also confirmed in our study, although there are some differences in sample preparation between the studies, but the solvents showed the same activity order.

In Figure 2, we presented the scavenging capacity (\%) of investigated extracts, at two different concentrations -1.0 and $5.0 \mathrm{mg} / \mathrm{ml}$.

Fazio et al. in their work showed that the methanolic seed extracts of Sambucus nigra exhibited a significant antioxidant capacity using the DPPH method [24].

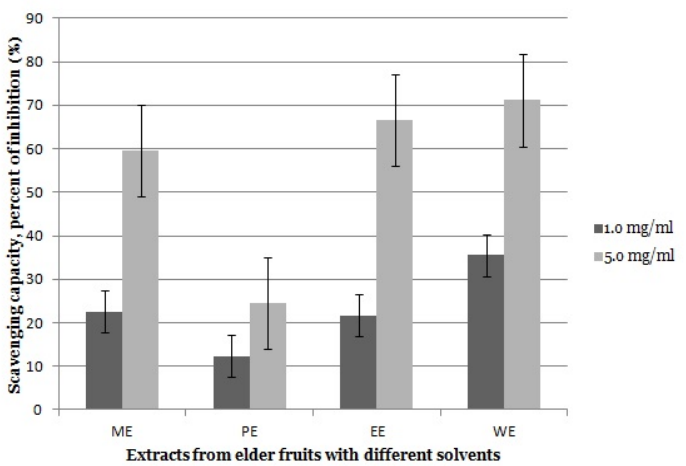

Figure 2. DPPH scavenging activities of elder fruit extracts at concentrations of 1.0 and $5.0 \mathrm{mg} / \mathrm{ml}$

The FRAP assay is used for the assessment of the ferric reducing potential of antioxidants. It is based on the reduction of the ferric ions to the ferrous ions in acidic medium, which form ferrous-tripyridyltriazine complex with an intensely blue colour [25]. Total FRAP values were calculated from the calibration curve equation using the standard $\mathrm{FeSO}_{4} \times 7 \mathrm{H}_{2} \mathrm{O}$ solution $\left(y=0.722 x+0.0594, r^{2}=0.993\right)$. In all experiments, reducing activity increased with the increasing concentrations of the fruit extracts. Sample WE showed the highest FRAP value. Extracts EE and ME showed lower FRAP values. The propylene glycolic extract exhibited the lowest capacity to reduce reactive species (Table 2). We used L-ascorbic acid and BHT as positive controls, which had FRAP values $27.90 \pm 0.38$ and $18.10 \pm 0.43 \mathrm{mmol} \mathrm{Fe}^{2+} / \mathrm{g}$, respectively.

Juice from Sambucus nigra fruit exhibits high ferric reducing potential, in comparison with juices from other plant fruits [26].

Table 2. Ferric Reducing Antioxidant Potential (FRAP) of the fruit extracts of Sambucus nigra. Values are expressed as mean $\pm \mathrm{SD}(\mathrm{n}=3)$

\begin{tabular}{|l|c|}
\hline Sample (solvent) & $\begin{array}{c}\mathrm{FRAP}(\mu \mathrm{mol} \\
\mathrm{Fe}^{2+} / \mathrm{g} \text { of dry } \\
\text { extract) }\end{array}$ \\
\hline ME (methanol) & $686.43 \pm 1.39^{*}$ \\
PE (propylene glycol 45\% v/v) & $242.29 \pm 0.80^{*}$ \\
EE (ethanol 70\% v/v) & $793.54 \pm 2.12^{*}$ \\
WE (distilled water) & $934.81 \pm 1.60^{*}$ \\
\hline
\end{tabular}

The $\beta$-carotene bleaching method is based on the discoloration of $\beta$-carotene in the absence of antioxidants, which leads to the reduction in the absorbance. So, the presence of antioxidant compounds in extracts can reduce the $\beta$-carotene bleaching due to neutralization of free radicals produced by linoleic acid during the incubation [27].

Our results showed that sample EE had the highest antioxidant activity, which is in accordance with the results of Gamze Duymus et al. [10]. In both studies the order of solvents and their antioxidant activity was similar. Extracts PE and WE showed the small capacity for inhibition of $\beta$-carotene bleaching (Table 3). Positive control was BHT which $\mathrm{IC}_{50}$ was $0.0108 \pm 0.0004 \mathrm{mg} / \mathrm{ml}$.

Table 3. Antioxidant activity of extracts of Sambucus nigra using the $\beta$-carotene bleaching method. Values are expressed as mean $\pm \operatorname{SD}(n=3)$

\begin{tabular}{|l|c|}
\hline Sample (solvent) & IC50 (mg/ml) \\
\hline ME (methanol) & $0.371 \pm 0.005^{*}$ \\
PE (propylene glycol 45\% v/v) & $0.547 \pm 0.007^{*}$ \\
EE (ethanol 70\% v/v) & $0.235 \pm 0.004^{*}$ \\
WE (distilled water) & $0.584 \pm 0.005^{*}$ \\
\hline
\end{tabular}

The antioxidant properties and neutralization of free radicals of alcoholic extracts from the leaves, berries and flowers of Sambucus nigra are confirmed by Dawidowicz et al. [28].

There is significant correlation between the FRAP values and the radical scavenging activity IC5O (Pearson correlation coefficient $\mathrm{r}=-0.975$ at $\mathrm{p} \leq 0.05$ ) (see Figure 3). The significant negative correlation $(\mathrm{y}=$ - 66.51x $\left.+1032.9, \mathrm{r}^{2}=0.9512\right)$ indicates that an increase in $\mathrm{IC}_{50} \mathrm{O}$ values was followed by a decrease in FRAP results.

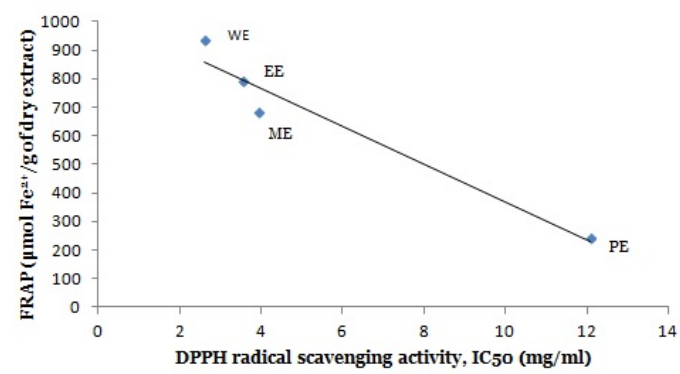

Figure 3. Correlation between FRAP assay and DPPH radical scavenging capacity (IC50 values); significant $(\mathrm{p}<0.05)$ negative correlation $(\mathrm{r}=-0.975)$

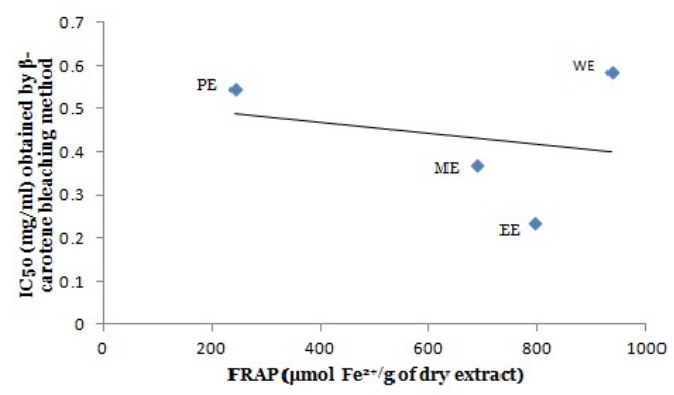

Figure 4. Correlation between IC50 values obtained by $\beta$ carotene bleaching assay and FRAP values; negative correlation $(r=-0.234)$ 
There is a negligible negative correlation between the FRAP values and IC50 values obtained by $\beta$-carotene bleaching assay (Pearson correlation coefficient $r=-0.234$ ) (Figure 4 ), and weak positive correlation between radical scavenging capacity and IC50 values obtained by $\beta$-carotene bleaching assay $(\mathrm{r}=0.372)$ (Figure 5).

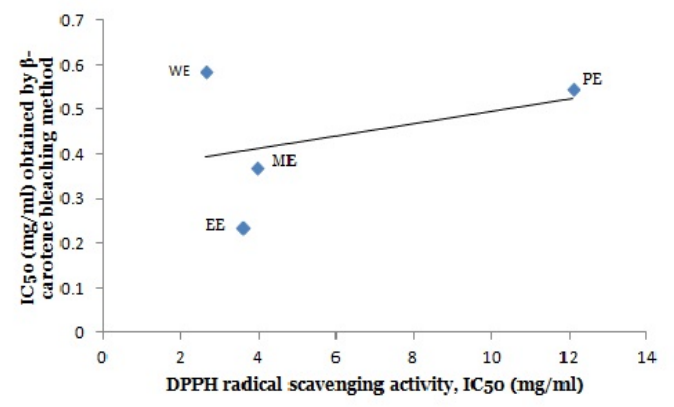

Figure 5. Correlation between IC50 values obtained by $\beta$-carotene bleaching assay and DPPH radical scavenging capacity (IC50 values); positive correlation $(\mathrm{r}=0.372)$

Bratuu et al. investigated antioxidant capacity of Sambucus nigra fruit powder by a photochemiluminescence method. They showed that powder had a very high in vitro antioxidant activity at low concentrations and they recommended it for applications in the food industry [29].

Some researchers were investigated Sambucus nigra fruit juice. They found that elderberry juices showed the higher content of total phenolic compounds, proanthocyanidins and antioxidant capacity (which they measured by three different methods) in comparison with other juice samples [26].

The evaluation of different solvents for extraction is a valuable source of information, as the results show clearly that the extraction agents significantly affect the antioxidant activity of elderberry extracts. The extract WE, i.e. distilled water used for extraction, was shown to be superior in extracting the antioxidant compounds in elderberries.

Gamze Dumus et al. in their study concluded that water extracts were rich in phenolic content and had the highest amount of anthocyanins, so they suggest their use as antioxidants [10].

In our work, the highest DPPH scavenging activity and FRAP activity was observed in the WE sample. In $\beta$-carotene bleaching assay, alcoholic extracts had higher IC50 values, but in general, all extracts had satisfactory antioxidant capacity. Obviously, solvent has been reported to have a great influence on the antioxidant activity of fruit extracts.

\section{CONCLUSION}

In summary, Sambucus nigra fruit extract, especially the one with distilled water (WE), was seen to be the effective in terms of antioxidant activity, but also from the dermatological aspect. This study shows that the water extraction method is a promising technique to isolate natural antioxidant compounds from elder fruits. These extracts can be used as a natural protective ingredient in skin formulation against harmful solar radiations. Due to its antioxidant and photoprotective properties, Sambucus nigra is a promising candidate for use in cosmetic and pharmaceutical formulations and it remains a challenge to effectively incorporate this extract in skin care and sunscreen formulations.

Acknowledgement: This study was supported by the Serbian Ministry of Science and Technological Development (project No. 45017).

\section{REFERENCES}

1. Y. Matsumura, H. N. Ananthaswamy, "Toxic effects of ultraviolet radiation on the skin," Toxicol. Appl. Pharmacol., vol. 195, no. 3, pp. 298 - 308, Mar. 2004. DOI: 10.1016/j.taap.2003.08.019 PMid: 15020192

2. J.A. Nichols, S. K. Katiyar, "Skin photoprotection by natural polyphenols: anti-inflammatory, antioxidant and DNA repair mechanisms," Arch. Dermatol. Res., vol. 302, no. 2, pp. $71-83$, Mar. 2010.

DOI: 10.1007/s00403-009-1001-3

PMid: 19898857 PMCid: PMC2813915

3. F. Afaq, H. Mukhtar, "Botanical antioxidants in the prevention of photocarcinogenesis and photoaging," Exp. Dermatol., vol. 15, no. 9, pp. 678 - 684, Sep. 2006. DOI: 10.1111/j.1600-0625.2006.00466.x PMid: 16881964

4. L. Chen, J. Y. Hu, S. Q. Wang, "The role of antioxidants in photoprotection: A critical review," J. Am. Acad. Dermatol., vol. 67, no. 5, pp. 1013 - 1024, Nov. 2012. DOI: 10.1016/j.jaad.2012.02.009 PMid: 22406231

5. V.V. da Silva et al., "Chemical stability and SPF determination of Pothomorphe umbellata extract gel and photostability of 4-nerolidylcathecol," Int. J. Pharm., vol. 303, no. 1-2, pp. 125 - 131, Oct. 2005.

DOI: 10.1016/j.ijpharm.2005.07.006 PMid: 16129576

6. R. Stevanato, M. Bertelle, S. Fabris, "Photoprotective characteristics of natural antioxidant polyphenols," Regul. Toxicol. Pharmacol., vol. 69, no. 1, pp. $71-77$, Jun. 2014.

DOI: 10.1016/j.yrtph.2014.02.014

PMid: 24607767

7. A. Jarzycka, A. Lewinska, R. Gancarz, K. A. Wilk, "Assessment of extracts of Helichrysum arenarium, Crataegus monogyna, Sambucus nigra in photoprotective UVA and UVB; photostability in cosmetic emulsions," J. Photochem. Photobiol. B, vol. 128, pp. 50 57, Nov. 2013.

DOI: 10.1016/j.jphotobiol.2013.07.029 PMid: 24007865

8. M. Radice et al., "Herbal extracts, lichens and biomolecules as natural photo-protection alternatives to synthetic UV filters. A systematic review," Fitoterapia, vol. 114, pp. 144 - 162, Oct. 2016.

DOI: 10.1016/j.fitote.2016.09.003 PMid: 27642040

9. S. Hu, X. Zhang, F. Chen, M. Wang, "Dietary polyphenols as photoprotective agents against UV radiation," J. Funct. Foods, vol. 30, pp. 108 - 118, Mar. 2017. DOI: 10.1016/j.jff.2017.01.009

10. H. G. Duymus, F. Goger, K. H. Can Baser, "In vitro antioxidant properties and anthocyanin compositions of elderberry extracts," Food Chem., vol. 155, pp. 112 - 119, Jul. 2014.

DOI: 10.1016/j.foodchem.2014.01.028

PMid: 24594162 
11. S. Jarić et al., "An ethnobotanical study on the usage of wild medicinal herbs from Kopaonik Mountain (Central Serbia)," J. Ethnopharmacol., vol. 111, no. 1, pp. $160-$ 170, Apr. 2007.

DOI: 10.1016/j.jep.2006.11.007

PMid: 17145148

12. R. E. U. Manganelli, L. Zaccaro, P. E. Tomei, “Antiviral activity in vitro of Urtica dioica L., Parietaria diffusa M. et K. and Sambucus nigra L.," J. Ethnopharmacol., vol. 98 , no. 3, pp. $323-327$, Apr. 2005.

DOI: 10.1016/j.jep.2005.01.021 PMid: 15814267

13. B. Roschek, R. C. Fink, M. D. McMichael, D. Li, R. S. Alberte, "Elderberry flavonoids bind to and prevent H1N1 infection in vitro," Phytochemistry, vol. 70, no. 10, pp. 1255 - 1261, Jul. 2009.

DOI: 10.1016/j.phytochem.2009.06.003 PMid: 19682714

14. A. Sidor, A. Gramza-Michałowska, "Advanced research on the antioxidant and health benefit of elderberry (Sambucus nigra) in food - a review," J. Funct. Foods, vol. 18 , pp. $941-958$, Oct. 2015 DOI: $10.1016 / j$.jff.2014.07.012

15. R. Veberic, J. Jakopic, F. Stampar, V. Schmitzer, "European elderberry (Sambucus nigra L.) rich in sugars, organic acids, anthocyanins and selected polyphenols," Food Chem., vol. 114, no. 2, pp. 511 - 515, May 2009. DOI: 10.1016/j.foodchem.2008.09.080

16. S. H. Nile, S. W. Park, "Edible berries: bioactive components and their effect on human health," Nutrition, vol. 3o, no. 2, pp. $134-144$, Feb. 2014.

DOI: 10.1016/j.nut.2013.04.007

PMid: 24012283

17. J. C. Espin, C. Soler-Rivas, H. J. Wichers, "Characterization of the Total Free Radical Scavenger Capacity of Vegetable Oils and Oil Fractions Using 2,2Diphenyl-1-picrylhydrazyl Radical," J. Agric. Food Chem., vol. 48 , no. 3 , pp. 648 - 656, Mar. 2000.

DOI: $10.1021 /$ jf 9908188

PMid: 10725129

18. I. F. F. Benzie, J. J. Strain, "The Ferric Reducing Ability of Plasma (FRAP) as a Measure of "Antioxidant Power": The FRAP Assay,” Anal. Biochem., vol. 239, no. 1, pp. $70-76$, Jul. 1996.

DOI: $10.1006 /$ abio.1996.0292 PMid: 8660627

19. I. I. Koleva, T. A. van Beek, J. P. H. Linssen, A. de Groot, L. N. Evstatieva, "Screening of Plant Extracts for Antioxidant Activity: a Comparative Study on Three Testing Methods," Phytochem. Anal., vol. 13, no. 1, pp. 8 - 17, Jan-Feb. 2002.

DOI: $10.1002 /$ pca.611 PMid: 11899609

20. J. A. Mendiola et al., "Screening of functional compounds in supercritical fluid extracts from Spirulina platensis," Food Chem., vol. 102, no. 4, pp. $1357-1367,2007$. DOI: 10.1016/j.foodchem.2006.06.068

21. S. M. Stajčić et al., "Chemical composition and antioxidant activity of berry fruits," APTEFF, no. 43, pp. 93 - 105, Oct. 2012.

DOI: $10.2298 / \mathrm{APT} 1243093 \mathrm{~S}$
22. N. F. Omar et al., "Phenolics, Flavonoids, Antioxidant Activity and Cyanogenic Glycosides of Organic and Mineral-base Fertilized Cassava Tubers," Molecules, vol. 17, no. 3, pp. 2378 - 2387, Feb. 2012.

DOI: $10.3390 /$ molecules17032378 PMid: 22370524

23. I. Gulcin, M. Elmastas, H. Y. Aboul-Enein, "Antioxidant activity of clove oil - A powerful antioxidant source," Arab. J. Chem., vol. 5, no. 4, pp. 489 - 499, Oct. 2012. DOI: 10.1016/j.arabjc.2010.09.016

24. A. Fazio, P. Plastina, J. Meijerink, R. F. Witkamp, B. Gabriele, "Comparative analyses of seeds of wild fruits of Rubus and Sambucus species from Southern Italy: fatty acid composition of the oil, total phenolic content, antioxidant and anti-inflammatory properties of the methanolic extracts," Food Chem., vol. 140, no. 4, pp. $817-824$, Oct. 2013

DOI: 10.1016/j.foodchem.2012.11.010 PMid: 23692771

25. R. Mogana, K. Teng-Jin, C. Wiart, “Anti-Inflammatory, Anticholinesterase, and Antioxidant Potential of Scopoletin Isolated From Canarium Patentinervium Miq. (Burseraceae Kunth)," Evid. Based Complement. Alternat. Med., vol. 2013, pp. 1 - 7, Jun. 2013.

DOI: $10.1155 / 2013 / 734824$

PMid: 23878606

PMCid: PMC3708431

26. D. Granato, A. R. Karnopp, S. M. van Ruth, "Characterization and comparison of phenolic composition, antioxidant capacity and instrumental taste profile of juices from different botanical origins," J. Sci. Food Agric., vol. 95, no. 10, pp. 1997 - 2006, Aug. 2015.

DOI: $10.1002 /$ jsfa.6910

PMid: 25213811

27. A. M. Maisarah, N. B. Amira, R. Asmah, O. Fauziah, "Antioxidant analysis of different parts of Carica papaya," Int. Food Res. J., vol. 20, no. 3, pp. 1043 1048, Jan. 2013.

Retrieved from: http://www.ifrj.upm.edu.my/20\%20(03 \%202013/8\%20IFRJ\%2020\%20(03)\%202013\%20Asm ah\%20(306).pdf

Retrieved on: Jan. 20, 2017

28. A. L. Dawidowicz, D. Wianowska, B. Baraniak, "The antioxidant properties of alcoholic extracts from Sambucus nigra L. (antioxidant properties of extracts)," LWT - Food Science and Technology, vol. 39, no. 3, pp. $308-315$, Apr. 2006. DOI: $10.1016 /$ j.lwt.2005.01.005

29. M. M. Bratu, E. Doroftei, T. Negreanu-Pirjol, C. Hostina, S. Porta, "Determination of Antioxidant Activity and Toxicity of Sambucus nigra Fruit Extract Using Alternative Methods," Food Technol. Biotechnol. vol. 50, no. 2, pp. 177 - 182, Apr. 2012. Retrieved from: http://hrcak.srce.hr/file/124750 Retrieved on: Jan. 20, 2017 